\title{
Prevalence and predictors of antibiotic prescription errors in an emergency department, Central Saudi Arabia
}

This article was published in the following Dove Press journal:

Drug, Healthcare and Patient Safety

4 June 2015

Number of times this article has been viewed

\author{
Menyfah Q Alanazi' \\ Majed I Al-Jeraisy ${ }^{2,3}$ \\ Mahmoud Salam² \\ 'Drug Policy and Economic Center, \\ ${ }^{2}$ King Abdullah International Medical \\ Research Center (KAIMRC), ${ }^{3}$ King \\ Saud bin Abdulaziz University for \\ Health Sciences (KSAU-HS), Riyadh, \\ Saudi Arabia
}

Background: Inappropriate antibiotic (ATB) prescriptions are a threat to patients, leading to adverse drug reactions, bacterial resistance, and subsequently, elevated hospital costs. Our aim was to evaluate ATB prescriptions in an emergency department of a tertiary care facility.

Methods: A cross-sectional study was conducted by reviewing charts of patients complaining of infections. Patient characteristics (age, sex, weight, allergy, infection type) and prescription characteristics (class, dose, frequency, duration) were evaluated for appropriateness based on the AHFS Drug Information and the Drug Information Handbook. Descriptive and analytic statistics were applied.

Results: Sample with equal sex distribution constituted of 5,752 cases: adults ( $\geq 15$ years) $=61 \%$ and pediatrics $(<15$ years $)=39 \%$. Around $55 \%$ complained of respiratory tract infections, $25 \%$ urinary tract infections (UTIs), and 20\% others. Broad-spectrum coverage ATBs were prescribed for $76 \%$ of the cases. Before the prescription, $82 \%$ of pediatrics had their weight taken, while $18 \%$ had their weight estimated. Allergy checking was done in $8 \%$ only. Prevalence of inappropriate ATB prescriptions with at least one type of error was $46.2 \%$ (pediatrics $=58 \%$ and adults $=39 \%$ ). Errors were in ATB selection (2\%), dosage (22\%), frequency (4\%), and duration (29\%). Dosage and duration errors were significantly predominant among pediatrics $(P<0.001$ and $P<0.0001$, respectively). Selection error was higher among adults $(P=0.001)$. Age stratification and binary logistic regression were applied. Significant predictors of inappropriate prescriptions were associated with: 1 ) cephalosporin prescriptions (adults: $P<0.001$, adjusted odds ratio [adj OR] =3.31) (pediatrics: $P<0.001$, adj OR =4.12) compared to penicillin; 2 ) UTIs (adults: $P<0.001$, adj $\mathrm{OR}=2.78$ ) (pediatrics: $P=0.039$, adj $\mathrm{OR}=0.73$ ) compared to respiratory tract infections; 3$)$ obtaining weight for pediatrics before the prescription of ATB $(P<0.001$, adj $\mathrm{OR}=1.83$ ) compared to those whose weight was estimated; and 4) broad-spectrum ATBs in adults $(P=0.002$, adj $\mathrm{OR}=0.67)$.

Conclusion: Prevalence of ATB prescription errors in this emergency department was generally high and was particularly common with cephalosporin, narrow-spectrum ATBs, and UTI infections.

Keywords: antibiotic, prescription, errors, prevalence, predictors, emergency

\section{Background}

Antibiotics (ATBs) are widely prescribed therapeutic agents given as treatments for a range of bacterial infections, especially to those admitted to emergency departments (EDs). EDs play an important role in delivering frontline health care services to a variety of patient populations and, in particular, to the vulnerable groups such as children, geriatrics, and others. ${ }^{1}$ It is estimated that 26 million ATBs are being prescribed 
annually in EDs over the world, which often result in adverse drug reactions, emergence of resistant bacteria, delay or failure in treatment, and subsequently, an increase in the direct health care costs. ${ }^{2-5}$

ATBs prescribed by general practitioners for children are estimated to be unnecessary most of the time. ${ }^{6}$ Although studies regarding the utilization of antimicrobials in EDs are few, there is recent evidence of inappropriate ATB usage in up to $50 \%$ of patients admitted to a typical ED setting with a community-acquired pneumonia. ${ }^{7}$ In fact, studies noted that the overuse and/or misuse of ATBs may even alter the ATB efficacy. ${ }^{8}$ These drugs fail when they are prescribed either for conditions that are not indicated for or even at suboptimal regimens, ${ }^{9}$ thus prolonging the suffering of patients. ${ }^{10}$

The vital therapeutic role of ATBs coupled with the ongoing threat of bacterial resistance is a compelling reason demanding adequate and appropriate usage of these drugs. Unfortunately, there are relatively very few studies that investigated the issue of inappropriate ATB usage in EDs within Saudi Arabia, a community that had an average (per individual) of 4.8 health care visits and $12.1 \%$ inpatient admission rate in 2010. ${ }^{11}$ Evaluating ATB prescriptions and identifying errors should be accounted as a primary care initiative for any health care facility to provide safer therapeutic regimens for patients individually and to eliminate the emergence of resistant bacteria globally. ${ }^{7}$

\section{Purpose of study}

The purpose of this study was to assess the prevalence and predictors of ATB-related prescription errors among patients admitted to an emergency center at a tertiary health care facility in the central region of the Kingdom of Saudi Arabia. This was achieved by fulfilling the following objectives: 1) screening patients with infections; 2) evaluating individual ATB prescriptions based on two clinical drug guidelines; and 3 ) identifying the prevalence of various types of committed prescription errors and their associated predictors.

\section{Methods}

\section{Study design}

This is a cross-sectional study, in which a review of patients' charts was done to identify patients complaining of infections and their prescribed ATB orders.

\section{Study area/setting}

King Abdulaziz Medical City (KAMC) is a distinguished Joint Commission International (JCI) accredited health care provider established since 1983 and under the umbrella of the
Ministry of National Guard (MNG). With a total bed capacity exceeding 1,169 beds, the ED at KAMC has 90 beds allocated for adult/pediatric wards of various care levels (observation, urgent, emergency to critical). ${ }^{12}$ A team of more than 80 emergency specialized consultants, associate consultants, assistant consultants, staff physicians, fellows, and residents provides services to 36,069 ED admissions annually with over 150,000 medication prescriptions.

\section{Study subjects and sampling technique}

Consecutive sampling was done by screening all patients' charts who were admitted to ED during the first quarter of 2008 starting from January 1 to March 30. Patients who fit the study criteria were of all ages ranging from 6 months to 65 years, registered at KAMC with a medical record number (MRN) and diagnosed with any type of infection that had been clearly documented in the patients' charts. Patients' charts with ATB prescriptions that were either incomplete (eg, missing ATB dosage or frequency) or had illegible handwriting were excluded. Infants with weight less than $5 \mathrm{~kg}$ were excluded too. ATB prescriptions were handwritten by physicians on a hospital form upon discharge. Prescriptions are generally cashed from the inhospital pharmacy, and are free for eligible patients with MRNs. Whether the prescription was cashed inside or outside the hospital pharmacy, the study aim was to evaluate the prescription form itself with no interest in following up on the cashing process.

\section{Data collection}

The data collection team composed of three research coordinators who were full-time employees at King Abdullah International Medical Research Center (KAIMRC) and who have passed a certified clinical research coordination course, International Commission on Harmonization in Good Clinical Practice certification, and other local mandatory certifications. The data collection team was trained by the authors on how to access, screen, and select eligible charts of patients from the medical records as well as how to document the findings on the data collection sheets. The evaluation of each ATB prescription was done by the consensus of two certified masters prepared pharmacists with extensive research and clinical experience using two internationally recognized and published drug guidebooks: 1) AHFS Drug Information (2008) from the American Society of HealthSystem Pharmacists ${ }^{13}$ and 2) Drug Information Handbook: A Comprehensive Resource for All Clinicians and Health Care Professionals, 15th edition, 2007. ${ }^{14}$ The data collected constituted of the following: 
1. Patient characteristics: MRN, age, sex, obtaining of weight prior prescription, checking for allergy status, and type of infection. All patient characteristics are electronically stored and updated on the hospital database. Weight is obtained upon each patient's visit as part of the primary health checkup prior appointment or admission. Allergy status of the patients is recorded as positive/negative for a certain ATB category or as an unknown status. Allergy screening of patients in this setting relies mainly on patient-recalled previous history of drug reactions and seldom on intradermal injections or lab tests. Upon prescribing the ATB, the physician documents the allergy status on the ATB prescription forms that were reviewed later on in this study.

2. ATB prescription characteristics: ATB category, dosage, frequency, and duration of administration. A complete ATB prescription form should include, in addition to the patient characteristics, the name, dosage, duration of ATB course, and route of administration. Oral ATB prescriptions are mainly prescribed for patients who are discharged home from the ED.

3. Outcome characteristics: four main types of errors were identified - selection, dosage, frequency, and duration errors. Each ATB prescription was evaluated based on its indications (infection type), age and weight of the patient according to the guidelines stated in the two references. Selection errors were accounted for an ATB category not recommended for a certain type of infection. In dosage and duration errors, a margin of $\pm 5 \%$ dosing variability was allowed upon comparing the prescribed dosage and duration to the guidelines, beyond which it was identified as an error. Frequency error was referred to as either under or above the recommended daily consumption of ATB dose. The clinical pharmacists were able to validate the collected data and investigate further clinical characteristics by accessing the KAMC electronic medical record system called QuadraMed.

\section{Ethical issues}

Data collectors were full-time employees of KAMC's research facility; thus, preserving the confidentially of the patients' information is an essential norm of their job requirements. MRNs of enrolled patient charts were recorded to further investigate the validity of data collected and accurate evaluation of prescribed ATBs. No written consents were obtained as the study was a retrospective chart review. Patient's privacy and confidentiality of data were secured by the principle investigator. This study was approved by the
Institution Review Board of the Ministry of National Guard, Riyadh, Saudi Arabia (RR08/005).

\section{Data management and analysis}

The SPSS statistical software (Version 22; SPSS Inc., Chicago, IL, USA) was used for data entry and analysis. Bivariate analysis using Pearson's chi-square test and Fisher's exact test were used for categorical data such as age category, sex, ATB category, and others. The prevalence of errors (selection, dosage, frequency, and duration) was calculated first as mutually exclusive prevalences by dividing the number of errors over the number of ATB prescriptions multiplied by 100 . The prevalence of an inappropriate ATB prescription was accounted as a physician order with at least one type or more of errors divided by total number of prescriptions and multiplied by 100 . Conducting statistical analysis by comparing differences between sex groups does not reveal great scientific value, so the age group was approached instead. Operational definition of adults ( $\geq 15$ years) and pediatrics $(<15$ years) was adopted since it was used in a number of similar studies. ${ }^{15-17}$ Binary logistic regression was constructed to identify the significant predictors, adjusted odds ratios (adj ORs), and 95\% confidence intervals (CIs) for the predictors of inappropriate ATB prescriptions. Significance was considered at $P$-value $<0.05$.

\section{Results}

A total of 6,097 charts were initially selected. After excluding patients' charts with unclear orders or missing variables, 5,752 met the inclusion criteria.

\section{Patients and ATB prescription-related characteristics}

Equal sex distribution was observed. Adults ( $\geq 15$ years) were $60.7 \%$, whereas pediatrics ( $<15$ years) were $39.3 \%$. Patients complained mainly of respiratory tract infections (RTIs) and UTIs, $55.4 \%$ and $24.9 \%$, respectively. Other types of infections were observed at lower rates, including otitis media $11.4 \%$, dermatological infections $6.9 \%$, gynecological-related infections $0.8 \%$, and gastrointestinal infections $0.6 \%$. The two main infections were RTIs significantly higher in pediatrics $(56 \%)$ versus adults $(31 \%)(P<0.001)$ and UTIs observed in $52.8 \%$ of the pediatrics and $47.6 \%$ of the adults, with no significant age group differences $(P=0.128)$. Weight was obtained from all admitted adults, but it was taken in only $82.1 \%$ of pediatrics. Majority of patients were not screened for ATB allergies (92.1\%). Three main ATB categories were prescribed in both age groups: penicillin (pediatrics $=45.7 \%$, adults $=29.4 \%$ ), 
cephalosporin (pediatrics $=34.1 \%$, adults $=27.5 \%$ ), and macrolide (pediatrics $=18.3 \%$, adults $=21.0 \%$ ) with significant age group differences in all three, $P<0.001, P<0.001$, and $P=0.010$, respectively. Almost $76 \%$ of both age groups were given broad-spectrum coverage ATBs.

\section{Prevalence of ATB prescription errors}

The prevalence of inappropriate ATB prescriptions with at least one or more types of errors was $46.2 \%$, which was significantly higher among pediatrics $(57.8 \%)$ compared to adults $(38.7 \%)(P<0.001)$. Mutually exclusive prevalence of errors was the least in selection of proper ATB class $(2.0 \%)$, followed by frequency (4.2\%), dosage $(21.7 \%)$, and duration (28.6\%). Pediatrics were significantly exposed to higher prevalence of dosage and duration errors, $P<0.001$ and $P<0.001$, respectively, whereas adults showed significantly higher prevalence of selection errors $(P<0.001)$. No significant difference was observed among the age groups with regard to the prevalence of frequency errors $(P=0.074)$. Physicians tend to prescribe ATBs with higher than the recommended dosages and/or frequencies as seen in Table 1.

\section{Predictors of ATB prescription errors}

A series of bivariate analysis initially revealed that $77 \%$ of cephalosporin prescriptions in pediatrics significantly contracted higher errors than those prescribed in adults $(60.9 \%)$, $P<0.001$. Errors in ATBs prescribed for RTIs in pediatrics $(56 \%)$ were significantly higher than ATBs prescribed for adults $(31 \%), P<0.001$, However, no significant difference was observed among the age groups with regard to penicillin prescriptions $(P=0.363)$ and UTIs $(P=0.202)$. Also, obtaining weight for pediatrics prior prescriptions showed no significant difference in errors compared to pediatrics whose weight was estimated, $P=0.673$, neither for allergy $(P=0.279)$ nor for ATB spectrum $(P=0.106)$, Table 2.

Since age is accounted as the main confounder, stratification by age groups and binary logistic regression were constructed. In adults, weight was obtained for all, so the only significant predators were cephalosporin $(\operatorname{adj} \mathrm{OR}=3.31$, $\mathrm{CI}=2.70-4.06$ ), UTIs (adj OR $=2.78, \mathrm{CI}=2.27-3.40$ ), and broad-spectrum ATBs (adj OR =0.67, CI =0.52-0.86) compared to penicillin, RTIs, and narrow-spectrum ATBs, $P<0.001, P<0.001$, and $P=0.002$, respectively. On the other hand, in case of ATBs that were prescribed for pediatrics, significant predictors of errors occurred in the treatment of UTIs (adj OR $=0.73, \mathrm{CI}=0.54-0.98$ ) and cephalosporins (adj OR =4.12, $\mathrm{CI}=3.22-5.27$ ) when compared to RTIs and penicillins, $P=0.039$ and $P<0.001$, respectively. In addition,
Table I Prevalence of inappropriate antibiotic prescriptions and various types of errors compared by age groups

\begin{tabular}{|c|c|c|c|}
\hline & $\begin{array}{l}\text { Pediatrics } \\
\text { ( }<15 \text { years) }\end{array}$ & $\begin{array}{l}\text { Adults } \\
\text { ( } \geq 15 \text { years) }\end{array}$ & Total \\
\hline & n (\%) & n (\%) & $\mathbf{N}(\%)$ \\
\hline & $2,258(39.3)$ & $3,494(60.7)$ & $5,752(100.0)$ \\
\hline \multirow{2}{*}{$\begin{array}{l}\text { Inappropriate ATB } \\
\text { prescriptions }^{\#}\end{array}$} & I,306 (57.8) & I,35I (38.7) & $2,657(46.2)$ \\
\hline & \multicolumn{3}{|c|}{$\chi^{2}=202.848, P<0.00 I^{*}$} \\
\hline \multirow[t]{2}{*}{ Selection error** } & $29(1.3)$ & $88(2.5)$ & $117(2.0)$ \\
\hline & \multicolumn{3}{|c|}{$\chi^{2}=10.486, P=0.00 I^{*}$} \\
\hline Frequency error** & $81(3.6)$ & $159(4.6)$ & $240(4.2)$ \\
\hline$<$ Recommended & $35(1.6)$ & $77(2.2)$ & $112(1.9)$ \\
\hline \multirow[t]{2}{*}{$>$ Recommended } & $46(2.0)$ & $82(2.4)$ & $128(2.3)$ \\
\hline & \multicolumn{3}{|c|}{$\chi^{2}=3.184, P=0.074$} \\
\hline Dosage error** & $649(28.7)$ & $597(17.1)$ & $\mathrm{I}, 246(2 \mathrm{I} .7)$ \\
\hline$<$ Recommended & $294(13.0)$ & $69(2.0)$ & $363(6.3)$ \\
\hline \multirow[t]{2}{*}{$>$ Recommended } & 355 (I5.7) & $528(15.1)$ & $883(15.3)$ \\
\hline & \multicolumn{3}{|c|}{$\chi^{2}=109.8, P<0.001 *$} \\
\hline Duration error** & 871 (38.6) & $774(22.2)$ & $\mathrm{I}, 645(28.6)$ \\
\hline$<$ Recommended & $622(27.5)$ & $459(13.1)$ & I,08I (I8.8) \\
\hline \multirow[t]{2}{*}{$>$ Recommended } & $249(11.1)$ & $315(9.1)$ & $564(9.8)$ \\
\hline & \multicolumn{3}{|c|}{$\chi^{2}=\mid 81.1, P<0.00 I^{*}$} \\
\hline
\end{tabular}

Notes: *Age group difference statistically significant at $P$-value $<0.05$; **errors are mutually exclusive. ${ }^{\# A T B}$ prescription with at least one error. $\chi^{2}$, Pearson chi-square test.

Abbreviation: ATB, antibiotic.

pediatrics who have been screened for weight before prescription were significantly 1.83 times more likely to contract errors compared to those whose weight was estimated $(P<0.001)$, Table 3 .

\section{Discussion}

The chart review was done during the cold winter season (January-March), at which there is an increase in the rate of morbidity and mortality due to respiratory infections. ${ }^{18}$ This explains why the majority of the participants observed complained of RTIs (45.3\%), which may in return complicate into ear infections, ${ }^{19}$ such as otitis media (11.4\%). UTIs were the second leading cause, and as expected, it was predominant in adults and, in particular, females. ${ }^{20}$ Figures are similar to those in literature since UTI is considered to be one of the most common infections for which ATBs are prescribed. ${ }^{21}$ Study findings were consistent as high rates of UTIs were accompanied by high rates of cephalosporin prescriptions. ${ }^{22}$

Checking for and documenting the allergy status was observed in only $7.9 \%$ in both age groups, which is considered a risky approach to prescribe any type of medication. Although evaluation for drug allergy involves a risk-benefit analysis based on a patient-recalled history and medical condition, in a typical 3-month period, $92.1 \%$ of admitted 
Table 2 Bivariate analysis of inappropriate antibiotic prescriptions compared by age groups

\begin{tabular}{|c|c|c|c|c|c|}
\hline & $\begin{array}{l}\text { Sample } \\
\text { n (\%) } \\
5,752(100)\end{array}$ & $\begin{array}{l}\text { Inappropriate } \\
\text { ATBs in pediatrics } \\
\text { n (\%) } \\
\text { I,306 (57.8) }\end{array}$ & $\begin{array}{l}\text { Inappropriate } \\
\text { ATBs in adults } \\
n(\%) \\
I, 35 \mid(38.7)\end{array}$ & $\begin{array}{l}\text { Inappropriate } \\
\text { ATBs in total } \\
N(\%) \\
2,657(46.2)\end{array}$ & Statistical analysis \\
\hline \multicolumn{6}{|l|}{ Sex } \\
\hline Male & $2,799(48.7)$ & $764(59.5)$ & $566(37.4)$ & $1,330(47.5)$ & $\chi^{2}=3.847, P=0.498$ \\
\hline Female & $2,953(51.3)$ & $542(55.6)$ & 785 (39.7) & I,327 (44.9) & \\
\hline \multicolumn{6}{|l|}{ Infection type } \\
\hline Respiratory & $3,187(55.4)$ & $801(56.0)$ & $545(31.0)$ & $1,346(42.2)$ & $\chi^{2}=201.0, P<0.001 *$ \\
\hline Urinary & I,434 (24.9) & $142(52.8)$ & $555(47.6)$ & $697(48.6)$ & $\chi^{2}=2.319, P=0.202$ \\
\hline Middle ear & $656(11.4)$ & $298(68.2)$ & $79(36.1)$ & $377(57.4)$ & $\chi^{2}=61.58, P<0.00 I^{*}$ \\
\hline OB/GYN & $43(0.8)$ & I (25.0) & $2(5.1)$ & $3(7.0)$ & Fisher-ex, $P=0.519$ \\
\hline Skin & $396(6.9)$ & $50(49.5)$ & $150(50.8)$ & $200(50.5)$ & $\chi^{2}=0.054, P=0.815$ \\
\hline Gastrointestinal & $35(0.6)$ & $14(93.3)$ & $20(100.0)$ & $34(97.1)$ & Fisher-ex, $P=0.519$ \\
\hline \multicolumn{6}{|l|}{ Weight taken ${ }^{* *}$} \\
\hline Yes & $5,347(92.9)$ & $\mathrm{I}, 123(60.6)$ & $1,351(100)$ & $2,474(46.2)$ & $\chi^{2}=0.178, P=0.673$ \\
\hline No & $405(7.1)$ & $183(45.2)$ & $0(0)$ & I83 (45.I) & \\
\hline \multicolumn{6}{|l|}{ Allergy screen** } \\
\hline Yes & 457 (7.9) & 95 (53.9) & $105(37.4)$ & $200(43.7)$ & $\chi^{2}=1.178, P=0.279$ \\
\hline No & $5,295(92.1)$ & $\mathrm{I}, 2 \mathrm{II}(58.2)$ & I,246 (38.8) & $2,457(46.4)$ & \\
\hline \multicolumn{6}{|l|}{ ATB category } \\
\hline Penicillin & $2,062(35.8)$ & $466(45.0)$ & $442(43.0)$ & $908(44.0)$ & $\chi^{2}=0.825, P=0.363$ \\
\hline Cephalosporin & $|, 73|(30.1)$ & $592(77.0)$ & $586(60.9)$ & $\mathrm{I}, 178(68.6)$ & $\chi^{2}=57.33, P<0.001 *$ \\
\hline Macrolide & $\mathrm{I}, \mathrm{I} 49(20.0)$ & $231(55.4)$ & $117(16.0)$ & $348(30.3)$ & $\chi^{2}=195.4, P<0.001 *$ \\
\hline Quinolone & $639(11.1)$ & $7(46.7)$ & I7I (27.4) & $178(27.6)$ & $\chi^{2}=2.705, P=0.100$ \\
\hline Clindamycin & $26(0.5)$ & $0(0.0)$ & $16(64.0)$ & $16(6 \mid .5)$ & Fisher-ex, $P=0.769$ \\
\hline Nitrofurantoin & $68(1.2)$ & $0(0.0)$ & $7(10.8)$ & $7(10.3)$ & Fisher-ex, $P=0.999$ \\
\hline Sulfonamide & $70(1.2)$ & $9(52.9)$ & $10(18.9)$ & $19(27.1)$ & $\chi^{2}=0.024, P=0.876$ \\
\hline Tetracycline & $7(0.1)$ & I (I00.0) & $2(33.3)$ & $3(42.9)$ & Fisher-ex, $P=0.01 *$ \\
\hline \multicolumn{6}{|l|}{ ATB spectrum } \\
\hline Broad & $4,364(75.9)$ & $994(59.7)$ & I,048 (38.8) & $2,042(46.8)$ & $\chi^{2}=0.261, P=0.106$ \\
\hline Narrow & I,388 (24.I) & $312(52.5)$ & $303(38.2)$ & $615(44.3)$ & \\
\hline
\end{tabular}

Notes: *Age group difference statistically significant at $P$-value $<0.05$; **procedure performed prior ATB prescription. $\chi^{2}$, Pearson chi-square test. Abbreviations: ATB, antibiotic; OB/GYN, obstetrics and gynecology; Fisher-ex, Fisher's exact test.

patients in this study received ATBs that could have induced a drug allergy. Regional studies showed that the prevalence of these drug allergies ranged between $3.1 \%$ and $5.5 \%$ in one of the Saudi Arabian university hospitals, of which $36.9 \%-48.5 \%$ was induced by ATBs. ${ }^{23}$ ED physicians' lack of knowledge on previous history such as a misdiagnosed penicillin allergy may result in the use of less appropriate or more expensive ATBs, ${ }^{17}$ thus increasing the chance of prescription errors.

Obtaining weight among the pediatric group, in particular, is of great importance as inaccurate weight estimation may contribute to prescription errors such as over/under recommended dosages. In this study, although $82.1 \%$ of pediatrics had their weight obtained before the prescription of ATBs, $60.6 \%$ of this group contracted errors (adj $P<0.001)$. Weighing pediatrics was a significant predictor of errors, as the adjusted odds ratio was 1.83 times higher in the group of pediatrics whose weight was obtained by physicians compared to the group of pediatrics whose weight was estimated prior ATB prescriptions. Previous literature has reported that physicians, nurses, and parents are unreliable in estimating pediatric weights, mostly underestimating weights and thus administering ATBs below the therapeutics levels..$^{24,25}$ The findings of this study suggest that physicians miscalculated the proper ATB dosages despite obtaining weight before prescription, with tendency to commit over or under the recommended dosage errors in $15.4 \%$ or $6.3 \%$ of the cases, respectively. This entails either lack of compliance or knowledge with the international guidelines of ATB prescriptions.

The increased selection of broad-spectrum coverage ATBs makes sense since physicians in ED are usually uncertain of the patient's diagnosis. ${ }^{26} \mathrm{ED}$ patients are seldom requested to provide biological samples for culturing (such as sputum, urine), unless there is a plan for in-hospital admission where culture results can shift the ATB regimens to a 
Table 3 Age-adjusted logistic regression for all possible predictors of inappropriate antibiotic prescriptions

\begin{tabular}{|c|c|c|c|c|c|c|c|c|}
\hline & \multicolumn{8}{|c|}{ Binary logistic regression } \\
\hline & \multicolumn{4}{|l|}{ Adults } & \multicolumn{4}{|c|}{ Pediatrics } \\
\hline & Beta & SE & Adj $P$-value & Adj OR (95\% Cl) & Beta & SE & Adj $P$-value & Adj OR (95\% Cl) \\
\hline \multicolumn{9}{|l|}{ Sex } \\
\hline Female $^{\#}$ & -0.066 & 0.097 & 0.495 & $0.94(0.78-1.13)$ & 0.203 & 0.106 & 0.056 & $1.23(1.01-1.5 \mathrm{I})$ \\
\hline \multicolumn{9}{|l|}{ Male } \\
\hline \multicolumn{9}{|c|}{ Type of Infection } \\
\hline $\mathrm{RTI}^{\#}$ & 1.022 & 0.103 & $<0.00 I^{*}$ & $2.78(2.27-3.40)$ & -0.315 & 0.153 & $0.039 *$ & $0.73(0.54-0.98)$ \\
\hline \multicolumn{9}{|l|}{ UTI } \\
\hline \multicolumn{9}{|l|}{ ATB class } \\
\hline Penicillin\# & 1.197 & 0.104 & $<0.00 I^{*}$ & $3.31(2.70-4.06)$ & 1.415 & 0.126 & $<0.00 I^{*}$ & $4.12(3.22-5.27)$ \\
\hline \multicolumn{9}{|c|}{ Cephalosporin } \\
\hline \multicolumn{9}{|c|}{ ATB spectrum } \\
\hline Narrow ${ }^{\#}$ & -0.403 & 0.128 & $0.002^{*}$ & $0.67(0.52-0.86)$ & -0.002 & 0.123 & 0.988 & $1.01(0.78-1.27)$ \\
\hline \multicolumn{9}{|l|}{ Broad } \\
\hline \multicolumn{9}{|c|}{ Allergy screen } \\
\hline $\mathrm{No}^{\#}$ & 0.017 & 0.161 & 0.917 & $1.02(0.74-1.39)$ & -0.050 & 0.189 & 0.791 & $0.95(0.68-1.34)$ \\
\hline \multicolumn{9}{|l|}{ Yes } \\
\hline \multicolumn{9}{|c|}{ Weight taken } \\
\hline $\mathrm{No}^{\#}$ & - & - & - & - & 0.601 & 0.140 & $<0.00 I^{*}$ & $1.83(1.39-2.40)$ \\
\hline \multicolumn{9}{|l|}{ Yes } \\
\hline Constant & -0.738 & 0.125 & 0.000 & 0.478 & -0.748 & 0.164 & 0.000 & 0.473 \\
\hline
\end{tabular}

Note: *Statistically significant association. "Reference group.

Abbreviations: Beta, coefficient of determination; SE, standard error; Adj, adjusted; OR, odds ratio; Cl, confidence interval; RTI, respiratory tract infection; UTI, urinary tract infection; ATB, antibiotic.

narrow-spectrum ATB coverage. ATB spectrum was not a significant predictor of prescription errors in our study except in adults (adj $P<0.002)$ after regression and age stratification, yet literature states that broad-spectrum ATBs prescribed in an ambulatory setting among pediatrics were extremely common and frequently inappropriate in $23 \%$ of the times, accounting to $>10$ million visits in Utah, USA. ${ }^{27}$

Various types of errors were observed, ranging from errors in selection, frequency, dosage, and duration as per the recommendations of the two drug guidelines. ${ }^{13,14}$ Implications of each type depend on the severity of error and the clinical symptoms, such as allergies, gastrointestinal disturbances, renal/liver distress, etc, yet these were not monitored in this study. Selection errors were significantly higher in adults, whereas duration and dosage errors were higher in pediatrics (Table 1). Prescribing an inappropriate ATB category such as in $2.0 \%$ of our sample promotes ATB resistance in addition to other unwanted complications. For example, an orally recommended ATB that has been incorrectly replaced by an intravenously administered ATB will put a patient at higher risk to contract phlebitis and other peripheral intravenous catheter complications. ${ }^{28}$ In $15.4 \%$ of our sample, the ATB prescribed was over the recommended dosage, while in $6.3 \%$, it was below the recommended dosage. Whether less than or more than the recommended guidelines, patients are at risk of an ineffective treatment, overloading the body with chemicals, and leading to the emergence of resistant bacteria. ${ }^{29}$

Prevalence of errors was originally found to be more abundant in patients with UTIs and cephalosporin prescriptions. Regression in adults with UTIs revealed that the chances of errors was 2.78 higher than those with RTIs, which is similar to what the Centers for Disease Control and Prevention discovered in that clinicians made more potential errors in prescribing ATBs for UTIs. ${ }^{30}$ Similar to these study findings, researchers also found evidence of prescribing errors in one-third of ATB prescriptions for UTIs, often given without proper testing or evaluation. ${ }^{21}$

In this study, the two main ATB categories tested were penicillins and cephalosporins. Other ATB groups were dropped out from the binary regression model since penicillin and cephalosporin prescriptions sum up to $66 \%$ of the total sample size. Adults on cephalosporin prescriptions were 3.31 times more likely to be exposed to ATB prescription errors compared to penicillin prescriptions. Little evidence was found in literature that compares prevalence of errors between these two commonly used ATB groups. In pediatrics, the risk in the cephalosporin group rises by 4.12 times.

Overall, literature revealed that prevalence of medication errors observed in similar settings from the region (Arabian Gulf countries) ranged between 23.6 and 50.5 , up to $54 \%$. $^{31-34}$ 
In this study, the prevalence rate of $46.2 \%$ ATB prescriptions with at least one error was found to be relatively high. Lower prevalence of prescription errors was found in a neighboring academic hospital in Tehran, in which $22 \%$ of patients experienced at least one type of error, with more than half of them related to faulty prescriptions. ${ }^{34}$ However, findings in other studies were even higher than what we found, as an emergency center of a university hospital from Arizona stated 53.9\% prescription errors. ${ }^{33}$ EDs in health care facilities are keen to keep prevalence of medication errors to the minimum.

\section{Limitations}

The present study was conducted in one health care facility of the central region of Saudi Arabia that provides services to the community of National Guard and their dependents. This may limit its ability to be generalized to represent other settings. In addition, the study period mainly covered the winter season, so we fear there might be seasonal variations in terms of the rates of ED admissions and types of infections. Owing to the fact that prescriptions were handwritten on papers, illegible orders were dropped, which might have carried errors that the data collectors missed.

Furthermore, obtaining lab cultures from biological samples is the most accurate indicator of an infection, yet not all patients were diagnosed by cultures. In fact, patients are sometimes prescribed an ATB based on clinical examinations, symptoms, and ruled out diseases. The study team did not have an infectious disease specialist for better assessing these infections and its related management. Also, it was not feasible to account for the physicians' years of experience as a possible confounder. There was no follow-up on the consequences of these errors (ie, deaths and/or adverse events) as patients were discharged home and study design was based on a chart review.

The AHFS Drug Information (2008 edition) ${ }^{13}$ and Drug Information Handbook, 2007 (15th edition) ${ }^{14}$ were the two references existing during the time when the physicians prescribed the ATBs. Therefore, the decision of whether the prescription contained any type of error was based on the guidelines written in these older editions. The annual upto-date comparisons between the older and newer editions are announced by the publishers of these references, which revealed no updates related to the ATB categories investigated in this study. ${ }^{35,36}$ Accordingly, the findings of this study were considered valid based on the similarity between the older editions of 2007/2008 and the newer editions issued in 2015 .

\section{Conclusion}

Study findings were alarming as prevalence of inappropriate ATB prescriptions in this ED was high, especially among vulnerable groups such as pediatrics. This study assessed prescriptions that have been written in an ED where errors are seldom identified due to the fact that not all patients are admitted and obtain further lab investigations (cultures) but are rather discharged. This results in the physician having minimal chance of correcting any faulty prescription for ATB, or even better, preventing it from the beginning, whether it is documented or not, as patients will have left the health care system.

\section{Recommendations}

Carry on supplements or smart phone applications for drug guidebooks may be circulated among physicians so that proper ATB prescriptions are accurately matched with the clinical indications of the admitted patients. In addition, ED physicians are highly advised to consult with clinical pharmacists and infection experts to execute an appropriate prescription. Screening for allergies and weight, especially among pediatrics, should be attended to prior prescriptions.

Non-punitive reporting and frequent quality audits on documented ATB prescriptions ensure the health care system in KAMC is error-free and in compliance with the international drug guidelines. ${ }^{37} \mathrm{~A}$ computerized medication prescription system called Legacy has been developed and implemented at KAMC in August 2008, which better supports the clinical decision systems through structured communication between various health disciplines. This system generates a preprinted prescription form composed of strictly controlled parameters containing the full aspects of the ATB, thus avoiding any chances of a misspelled name, inappropriate dosage or frequency, route, and others. In addition, patient characteristics such as age, weight, and allergies are automatically generated by Legacy that sources it from the database of MRNs, therefore cautioning the physician on any missing parameter. This system also presents to the physicians the history of ATB prescriptions that has been provided to the same patient during previous ED visits. Findings of this study may be compared to other hospitals that still adopt the paper-based prescription system. In addition, a future pre-post test design study within the same hospital setting is highly recommended to locally evaluate the effectiveness of the Legacy system and then to compare it to the findings of other health care facilities that adopted prescription systems similar to Legacy. 
It is advisable that the prevalence of ATB prescription errors are accounted as hospital quality indicators, thus being monitored and benchmarked on a quarterly basis. Constructing large-scale registries targeting hospitals all over Saudi Arabia will aid in pooling valuable data that will generate evidence-based guidelines and promote up-to-date safer and better ATB prescription modalities.

\section{Acknowledgments}

This study was initiated and funded by King Abdullah International Medical Research Center and King Saud bin Abdulaziz University for Health Sciences, Riyadh, Saudi Arabia. The authors would like to thank the Research office and Institution Review Board for their tremendous support. Special thanks to Dr Mahmoud Elbarbary for his advisory role. Authors would like to thank the research coordinator Mr Mohammed Al-Assiri for his contributions in coordinating the data collection and Mr Daham Daham for organizing the data, as well as the staff of emergency department, pharmaceutical care department, and nursing department.

\section{Author information}

Menyfah Alanazi is a clinical pharmacy practitioner working at the Drug Policy and Economic Center of MNG. Majed Al-Jeraisy is a clinical pharmacy specialist and chairman of the research office of KAIMRC of MNG. Mahmoud Salam is a research coordinator of the Saudi National Biobanking Section at KAIMRC.

\section{Author contributions}

All authors contributed towards the study concept, data analysis, drafting, and revising of the paper and agreed to be accountable for all aspects of the work.

\section{Disclosure}

The authors declare that they have no competing interests in this work.

\section{References}

1. Organization WH. WHO Global Strategy for Containment of Antimicrobial Resistance. Geneva, Switzerland: WHO; 2001.

2. Doyne EO, Alfaro MP, Siegel RM, et al. A randomized controlled trial to change antibiotic prescribing patterns in a community. Arch Pediatr Adolesc Med. 2004;158(6):577-583.

3. Odenholt I, Bylander-Groth A, Frimodt-Möller N, Rökstad KS, Mölstad S. Differences in antibiotic prescribing patterns between general practitioners in Scandinavia: a questionnaire study. Scand J Infect Dis. 2002;34(8):602-609.

4. Schwartz B, Mainous AG, Marcy SM. Why do physicians prescribe antibiotics for children with upper respiratory tract infections? $J \mathrm{Am}$ Med Assoc. 1998;279:881-882.
5. McCaig LF, Burt CW. National Hospital Ambulatory Medical Care Survey: 1999 Emergency Department Summary. Atlanta, GA: Department of Health and Human Services, Centers for Disease Control and Prevention, National Center for Health Statistics; 2001.

6. Rossignoli A, Clavenna A, Bonati M. Antibiotic prescription and prevalence rate in the outpatient paediatric population: analysis of surveys published during 2000-2005. Eur J Clin Pharmacol. 2007;63(12): 1099-1106.

7. Malcolm C, Marrie TJ. Antibiotic therapy for ambulatory patients with community acquired pneumonia in an emergency department setting. Arch Int Med. 2003;163:797-802.

8. Mack A, Relman DA, Choffnes ER. Antibiotic Resistance: Implications for Global Health and Novel Intervention Strategies: Workshop Summary. National Academies Press: Washington, DC; 2010.

9. MacPherson DW, Gushulak BD, Baine WB, et al. Population mobility, globalization, and antimicrobial drug resistance. Emerg Infect Dis. 2009;15(11):1727.

10. WHO Organization. WHO Global Principles for the Containment of Antimicrobial Resistance in Animals Intended for Food: Report of a WHO Consultation with the Participation of the Food and Agriculture Organization of the United Nations and the Office International des Epizooties, June 5-9; 2000; Geneva, Switzerland.

11. Moh.gov.sa. Health Indicators for the Year of $1431 \mathrm{H}$. General Directorate of Statistics. Riyadh, Saudi Arabia: Ministry of Health in Saudi Arabia; 2010. Available from: http:/www.moh.gov.sa/en/ Ministry/Statistics/Indicator/Pages/Indicator-2012-01-10-0001.aspx. Accessed March 18, 2015.

12. Abolfotouh M, AlKelya M, AbuKhalid N, Salam M, Alamry A. Nursing perception towards impact of JCI accreditation and quality of care in a tertiary care hospital, Central Saudi Arabia. Int J Med Sci. 2014;47: $1447-1460$

13. AHFS Drug Information. In: McEvoy GK, editor. Scopolamine. Bethesda, MD: American Society of Health-System Pharmacists; 2008.

14. American Pharmacists Association. Drug Information Handbook. 16th ed. Hudson, OH: Lexicomp; 2007.

15. Resi D, Milandri M, Moro M. Antibiotic prescriptions in children. J Antimicrob Chemother. 2003;52(2):282-286.

16. Patrick DM, Marra F, Hutchinson J, Monnet DL, Ng H, Bowie WR. Per capita antibiotic consumption: how does a North American jurisdiction compare with Europe? Clin Infect Dis. 2004;39(1):11-17.

17. Marra F, Patrick DM, Chong M, Bowie WR. Antibiotic use among children in British Columbia, Canada. J Antimicrob Chemother. 2006;58(4):830-839.

18. Mourtzoukou E, Falagas M. Exposure to cold and respiratory tract infections [Review article]. Int J Tuberc Lung Dis. 2007;11(9):938-943.

19. Revai K, Dobbs LA, Nair S, Patel JA, Grady JJ, Chonmaitree T. Incidence of acute otitis media and sinusitis complicating upper respiratory tract infection: the effect of age. Pediatrics. 2007;119(6):e1408-e1412.

20. Lee JB, Neild GH. Urinary tract infection. Medicine. 2007;35(8): 423-428.

21. Live Science. Antibiotic Misuse in Hospitals Raises Patient Infection Risk by Rettner R; 2014. Available from: http://www.livescience.com/43845antibiotics-hospitals-infections.html. Accessed March 22, 2015.

22. Milo G, Katchman E, Paul M, Christiaens T, Baerheim A, Leibovici L. Duration of antibacterial treatment for uncomplicated urinary tract infection in women. J Urol. 2006;175(3):968.

23. Khan LM, Al-Harthi SE, Saadah OI, Al-Amoudi AB, Sulaiman MI, Ibrahim IM. Impact of pharmacovigilance on adverse drug reactions reporting in hospitalized internal medicine patients at Saudi Arabian teaching hospital. Saudi Med J. 2012;33(8):863-868.

24. Lim CAE, Kaufman BJ. Accuracy of weight estimates in pediatric patients by prehospital emergency medical services personnel. Am J Emerg Med. 2013;31(7):1108-1112.

25. Selbst SM, Fein JA, Osterhoudt K, Ho W. Medication errors in a pediatric emergency department. Pediatr Emerg Care. 1999;15(1):1-4. 
26. Vermont Department of Health (VDH) and Centers for Disease Control and Prevention (CDC). Antibiotic Stewardship in Emergency Departments Structured Interviews with Emergency Department Personnel in 12 Vermont Hospitals and Dartmouth Hitchcock Medical Center. Project report from VMS Education and Research Foundation: Vermont, USA; 2015.

27. Hersh AL, Shapiro DJ, Pavia AT, Shah SS. Antibiotic prescribing in ambulatory pediatrics in the United States. Pediatrics. 2011;128(6): 1053-1061.

28. Abolfotouh M, Salam M, Bani-Mustafa A, White D, Balkhy H. Prospective study of incidence and predictors of peripheral intravenous catheter-induced complications. Ther Clin Risk Manag. 2013;10: 993-1001.

29. Mayo Clinic. Antibiotics: Misuse Puts You and Others at Risk by Mayo Clinic Staff in Healthy Lifestyle: Consumer Health; 2014. Available from: http:/www.mayoclinic.org/healthy-living/consumer-health/indepth/antibiotics/art-20045720. Accessed March 22, 2015.

30. Center for Infectious Disease Research and Policy (CIDRAP). CDC Calls Out Antibiotic Prescribing Problems by Schnirring L; 2014. Available from: http://www.cidrap.umn.edu/news-perspective/2014/03/ cdc-calls-out-antibiotic-prescribing-problems. Accessed March 23, 2015.

31. Vazin A, Zamani Z, Hatam N. Frequency of medication errors in an emergency department of a large teaching hospital in southern Iran. Drug Healthc Patient Saf. 2014;6:179.
32. Zeraatchi A, Talebian M, Nejati A, Dashti-Khavidaki S. Frequency and types of the medication errors in an academic emergency department in Iran: the emergent need for clinical pharmacy services in emergency departments. J Res Pharm Prac. 2013;2(3):118.

33. Khalili H, Farsaei S, Rezaee H, Dashti-Khavidaki S. Role of clinical pharmacists' interventions in detection and prevention of medication errors in a medical ward. Int J Clin Pharm. 2011;33(2):281-284.

34. Dabaghzadeh F, Rashidian A, Torkamandi H, et al. Medication errors in an emergency department in a large teaching hospital in Tehran. Iran J Pharm Res. 2013;12(4):937.

35. AHFS Pharmacologic-Therapeutic Classification. New Drug Assignments/Reassignments of the 2015 edition. McEvoy GK, editor. Liotrix. Bethesda, MD: American Society of Health-System Pharmacists; 2015. Available from: http://www.ahfsdruginformation. com/drug-assignments.aspx. Accessed March 23, 2015.

36. Lexicomp. Revision Drug Information Handbook: A Comprehensive Resource for all Clinicians and Healthcare Professionals. 23rd ed; 2014. Available from: http://www.lexi.com/home/revisions. Accessed March 23, 2015.

37. Al-Jeraisy MI, Alanazi MQ, Abolfotouh MA. Medication prescribing errors in a pediatric inpatient tertiary care setting in Saudi Arabia. BMC Res Notes. 2011;4(1):294.
Drug, Healthcare and Patient Safety

\section{Publish your work in this journal}

Drug, Healthcare and Patient Safety is an international, peer-reviewed open-access journal exploring patient safety issues in the healthcare continuum from diagnostic and screening interventions through to treatment, drug therapy and surgery. The journal is characterized by the rapid reporting of reviews, original research, clinical, epidemiological and

\section{Dovepress}

post-marketing surveillance studies, risk management, health literacy and educational programs across all areas of healthcare delivery. The manuscript management system is completely online and includes a very quick and fair peer-review system. Visit http://www.dovepress.com/ testimonials.php to read real quotes from published authors. 